\title{
The Global Warming, Sustainability, and Environmental Tax: Dynamic General Equilibrium Model
}

\author{
Toshitaka Fukiharu \\ School of Social Informatics, Aoyamagakuin University \\ fukiharuasi.aoyama.ac.jp
}

\begin{abstract}
A primitive economic model with classical population theory is constructed in order to examine the greenhouse effect on the sustainability of human population as well as the environmental tax when the sustainability is in danger. The conclusion of this paper is that when the negative effect is small, the tax can guarantee the sustainability, where the effective tax rate interval for the sustainability shrinks as the negative effect rises. When the negative effect exceeds the critical level, however, the environmental tax cannot guarantee the sustainability of human population. Thus, the remedial measure to reduce the greenhouse effect other than the environmental tax is needed for the sustainability.
\end{abstract}

Keywords: general equilibrium, simulation, population, sustainability, environmental tax.

\section{Introduction}

The argument on the global warming through greenhouse effect gained momentum in the 1980s. Brown [1] warned the decline of food production due to the greenhouse effect. One of the main concerns of The Earth Summit in Rio de Janeiro in 1992 was whether the participants could agree to adopt the environmental tax on $\mathrm{CO}_{2}$ emission globally. The agreement was not reached. In 1995 the IPCC concluded that global warming is taking place due to human activity: greenhouse effect. The main aim of the 1997 Kyoto Protocol was to reach agreement for each country to reduce the global warming gases. Stern [7] still warned the decline of food production due to the greenhouse effect, while $\mathrm{CO}_{2}$ has the carbon fertilization effect.

In this paper, a primitive economic model is constructed in order to examine this greenhouse effect on the sustainability of human population, as well as the economic policies when the sustainability is in danger. This model is constructed in terms of dynamic general equilibrium (GE) approach.

\section{Economic Model and Short-Run Equilibrium}

In this model, there are two industries: food industry and energy industry. For simplicity the capital accumulation is omitted from the model. The food industry 
produces output (food), using labor and energy. The energy industry produces output (energy), using only labor. Two industries maximize profit. The aggregate household maximizes utility subject to income constraint, where the utility is a function of food and energy.

In the short run, the population (working hours) and the $\mathrm{CO}_{2}$ level are assumed to be constant. Given the population and $\mathrm{CO}_{2}$ level, it is guaranteed that general equilibrium prices exist which equate demand and supply in food and energy markets. Under these prices, energy is consumed, expanding $\mathrm{CO}_{2}$ level in the atmosphere. In the long run, the expanded $\mathrm{CO}_{2}$ level affects food production. Furthermore, population varies in the long run according to classical population theory, propounded by Malthus and Verhulst. We start with the formal model and the short run equilibrium.

\subsection{Formal Model}

A primitive general equilibrium (GE) model is constructed, for the purpose of examining the greenhouse effect. Suppose that there are two industries (firms). The first firm is a farm which produces food; $Z_{f}$. Whereas food is produced by labor: $L_{1}$, and energy: $H_{f 1}$, the output is affected by $\mathrm{CO}_{2}$ level: $Y$, in the atmosphere. Thus, this firm has the production function:

$$
Z_{f}=g_{1}\left[L_{1}, H_{f 1}, Y\right] \quad g_{11}>0, g_{12}>0
$$

where $g_{i j}$ is the partial derivative of $g_{i}$ with respect to the $j^{\text {th }}$ variable. It aims at the profit maximization:

$$
\max \pi_{1}=p Z_{f}-w L_{1}-p_{H} H_{f 1}
$$

where $p$ is the wheat price, $w$ is the wage rate, and $p_{H}$ is the energy price.

The second firm is the energy industry which produces energy: $H_{f 2}$, using only labor: $L_{2}$. It has the production function

$$
H_{f 2}=g_{2}\left[L_{2}\right] \quad g_{21}>0 \text {. }
$$

It aims at the profit maximization:

$$
\max \pi_{2}=p_{H} H_{f 2}-w L_{2}
$$

There is only one (representative) household, which consumes food: $Z_{h}$, and energy: $H_{h}$. Household maximizes utility subject to budget constraint:

$$
\max u\left[Z_{h}, H_{h}\right] \text { s.t. } p Z_{h}+p_{H} H_{h}=w N+\pi_{1}+\pi_{2}
$$

where $u\left[Z_{h}, H_{h}\right]$ is the utility function, and $N$ is the initial leisure hours (population), and $\pi_{i}$ is the profit from the $i^{\text {th }}$ firm $(i=1,2)$. For the sake of simplification, in this model, leisure consumption is excluded from the utility function.

\subsection{Short-Run GE and Specification of Functions}

Given $\mathrm{CO}_{2}$ level: $Y$, and $N$, the short-run General Equilibrium (SGE) is defined, which satisfies 


$$
\begin{aligned}
H_{f 1}{ }^{d}+H_{h}{ }^{d} & =H_{f 2}{ }^{s} & & \text { (energy market) } \\
Z_{h}{ }^{d} & =Z_{f}{ }^{s} & & \text { (wheat market) } \\
L_{1}{ }^{d}+L_{2}{ }^{d} & =N & & \text { (labor market) }
\end{aligned}
$$

where superscript $d(s)$ implies "demand" ("supply").

We assume that the production and utility functions are stipulated by the following.

$$
\begin{aligned}
g_{1}\left[L_{1}, H_{f 1}, Y\right] & =L_{1}^{\alpha 1} H_{f 1}{ }^{\alpha 2} A\left[Y, x_{0}\right]^{\alpha 3}, \quad \alpha_{1}+\alpha_{2}+\alpha_{3} \leq 1,0 \leq x_{0} \leq 1 \\
g_{2}\left[L_{2}\right] & =L_{2} \\
u\left[Z_{h}, H_{h}\right] & =Z_{h}^{\gamma} H_{h}{ }^{1-\gamma}, \quad 0<\gamma<1
\end{aligned}
$$

The function, $A\left[Y, x_{0}\right]$, is a negative factor from the greenhouse effect. Suppose that $Y[0]=1000$ is the present level of $\mathrm{CO}_{2}$ in the atmosphere. We specify that

$$
A\left[Y, x_{0}\right]=\operatorname{Min}\left[1,1-\left(1-e^{-Y / 1000}\right)^{5} x_{0}\right]
$$

When $x_{0}=1 / 10$, for example, $A[Y, 1 / 10]$ is depicted as in Figure 1 .

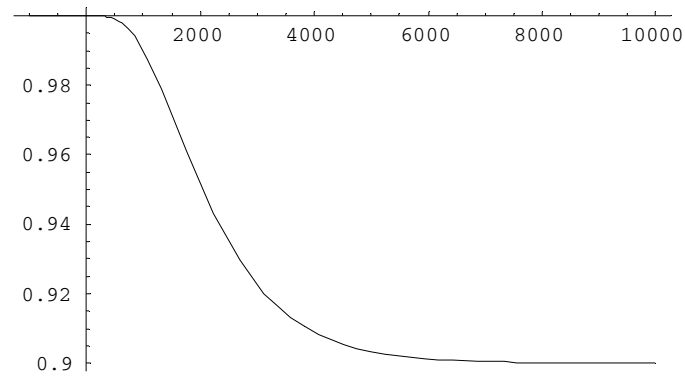

Fig. 1. $A[Y, 1 / 10]$ : Greenhouse Effect Factor

In this formulation, the relative price of energy, $p_{H} / p^{*}$, is determined at SGE, as in what follows.

$$
p_{H} / p^{*}=\left(\left(1-\gamma\left(1-\alpha_{1}-\alpha_{2}\right)\right) / \gamma N\right){ }^{1-\alpha 1-\alpha 2} \alpha_{1}{ }^{\alpha 1} \alpha_{2}{ }^{\alpha 2} A\left[Y-1000, x_{0}\right]^{\alpha 3}
$$

The SGE labor input for wheat, $L_{1}{ }^{*}$, is given as in what follows.

$$
L_{1}^{*}=\alpha_{1} \gamma N /\left(1-\gamma\left(1-\alpha_{1}-\alpha_{2}\right)\right)
$$

The SGE energy input for wheat, $H_{f 1} *$, is given as in what follows.

$$
H_{f 1} *=\alpha_{2} \gamma N /\left(1-\gamma\left(1-\alpha_{1}-\alpha_{2}\right)\right)
$$

The SGE energy consumption of household, $H_{h}{ }^{*}$, is given as in what follows.

$$
H_{h}{ }^{*}=(1-\gamma) N /\left(1-\gamma\left(1-\alpha_{1}-\alpha_{2}\right)\right)
$$


Also for the later use, the SGE wheat output, $g_{1}{ }^{*}$, is computed as in what follows.

$$
g_{1}^{*}=\alpha_{1}^{\alpha 1}\left(\alpha_{1}+\alpha_{2}\right)^{\alpha 2}(\gamma N)^{\alpha 1+\alpha 2} A\left[Y-1000, x_{0}\right]^{\alpha 3} /\left(\left(1-\gamma\left(1-\alpha_{1}-\alpha_{2}\right)\right)^{\alpha 1+\alpha 2} .\right.
$$

\section{Long-Run General Equilibrium Dynamics}

The analysis in the previous section is called the short-run general equilibrium model, $\mathrm{SGE}$, since two variables were fixed by the assumption. First, $\mathrm{CO}_{2}$ in the atmosphere: $Y$, was fixed. In fact, $\mathrm{CO}_{2}$ in the atmosphere increases through the use of energy in the household's direct consumption and farm's use of energy in the wheat production, while it decreases thanks to the absorption by the working of sea and the photosynthetic function of food. The variation of $\mathrm{CO}_{2}$ in the atmosphere, in turn, causes the variation of food output. Thus, the economic analysis of greenhouse effect must be constructed in terms of dynamic system.

Second, population was assumed to be constant in the previous section. In this section this assumption is relaxed. In "On Population", T.R.Malthus argued that population growth is expressed as the geometric progression; $1,2^{2}, 3^{2}, \ldots, n^{2}, \ldots$, while food production as the natural progression; $1,2,3, \ldots, n, \ldots$, since the latter is under diminishing marginal productivity. It was asserted that in the long run, a society's population growth is restricted by food production. In this section, this assertion is incorporated. However, the population cannot become infinite due to the capacity limit of the earth. Considering this limit, P.f. Verhulst proposed a different type of population growth model. In this section, population growth has two factors, the first of which is the one stemming from the Verhulst model, while the second is the one stemming from the Malthus model.

If we admit the variation of two variables, the previous model must be reformulated in terms of dynamic system, which is called the long-run general equilibrium dynamics (LGED). In this section, an extension of this sort is attempted.

\subsection{The Variation of $\mathrm{CO}_{2}$ in the Atmosphere}

Formally, as energy is produced, $Y$ : a in the atmosphere, increases by the amount of $F_{1}[H]$ where $H=H_{f 1}+H_{h}$, while $Y$ decreases, first, by the amount of $F_{2}[Y]$, thanks to the activity of the sea and forest, second, $F_{3}\left[g_{1}\right]$, thanks to the photosynthetic function of wheat. Thus, we have a dynamic system

$$
\mathrm{d} Y[t] / \mathrm{d} t=\mu_{1} H[t]-\mu_{2} Y[t]-\mu_{3} g_{1}[t]
$$

where $t$ stands for time and $\mu_{i}$ s are all positive constant $(i=1,23)$.

\subsection{The Variation of Population}

P.f. Verhulst assumed that the variation of population follows the differential equation: $\mathrm{d} N[t] / \mathrm{d} t=\varepsilon N[t](1-N[t] / K)$ where $N[t]$ is the population at time $t, K$ is the capacity limit for the population, and $\varepsilon$ is a positive parameter. In view of the Malthus' argument it is assumed that $K$ depends on the per-capita consumption of food when we reach $K$. In this process, $N[t]$ monotonically converges to $K$. Taking 
account of the Malthus argument, we assume the variation of population as in what follows where $\beta$ is a positive parameter.

$$
\mathrm{d} N[t] / \mathrm{d} t=\varepsilon N[t](1-N[t] / K)+\beta\left(\mathrm{d}\left(g_{1}\left[L_{1}[t], H_{f 1}[t], Y[t]\right] / N[t]\right) / \mathrm{d} t\right) N[t]
$$

It is assumed that if the per capita consumption of wheat decreases the population growth decreases: growth adjustment, and vice versa. The dynamic analysis in terms of differential equations, derived from (1), (2), (3), (4), (5), and (6), is called the longrun general equilibrium dynamics.

\section{Simulations}

In this section, simulations are attempted by specifying parameters. When $x_{0}=0$ or $\alpha_{3}=0$, the greenhouse effect is zero, which is the starting point of the present section. As the greenhouse effect is intensified, $x_{0}$ rises. Assuming $\alpha_{3}>0$, we conduct the simulations by raising $x_{0}$ from zero. In this simulation, the parameters are specified as in what follows.

$$
\alpha_{1}=1 / 4, \alpha_{2}=1 / 4, \varepsilon=1 / 1000, \gamma=1 / 2, \mu_{1}=1 / 5, \mu_{2}=1 / 100, \mu_{3}=1 / 100, K=1000000, \beta=1
$$

\subsection{Zero Greenhouse Effect Case}

When $x_{0}=0$ or $\alpha_{3}=0$ (the case of no greenhouse effect), the trajectory path of $\{N[t]$, $Y[t]\}$ on LGED, starting from the initial position, $\{N[0], Y[0]\}=\{1000,1000\}$, converges to $\left\{N^{*}, Y^{*}\right\}$, where $N^{*}=1000000$ and $Y^{*}=832573.39699090708710$. The trajectory path of per capita food production, $g_{1}[t] / N[t]$ on LGED, starting from the initial position, $\{N[0]), Y[0]\}=\{1000,1000\}$ is depicted in Figure 2. It converges to $\left(g_{1} / N\right) *=0.000408248$.

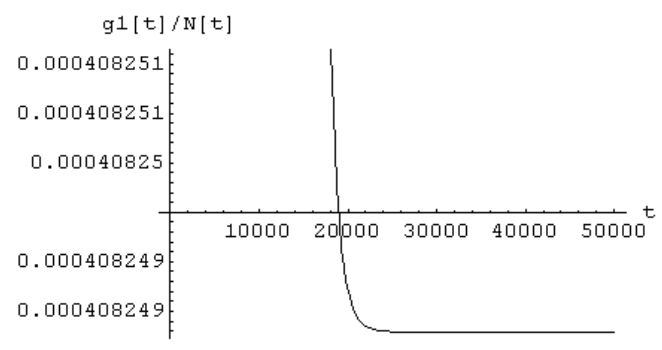

Fig. 2. Trajectory of Per Capita Consumption: $x_{0}=0$

It must be noted that population capacity, $K=1000000$, is sustainable only when the per capita consumption of wheat is at least $\left(g_{1} / N\right)^{*}$

\subsection{Active Greenhouse Effect Case: $\alpha_{3}=1 / 4$ and $\boldsymbol{x}_{\mathbf{0}}=\mathbf{1 / 1 0}$}

We examine what happen to the convergence on LGED when the greenhouse effect is positive. Suppose that $\alpha_{3}=1 / 4$ and $x_{0}=1 / 10$. The trajectory path of $\{N[t], Y[t]\}$ on 
LGED, starting from the initial position, $\{N[0], Y[0]\}=\{1000,1000\}$, converges to $\left\{N^{*}, Y^{*}[1 / 10]\right\}$, where $N^{*}=1000000$ and $Y^{*}[1 / 10]=16666269.0313023>Y^{*}$. The trajectory path of per capita food production, $g_{1}[t] / N[t]$ on LGED, starting from the initial position, $\{N[0]), \quad Y[0]\}=\{1000,1000\}$ converges to $\left(g_{1} / N\right) *[1 / 10]=$ $0.000397635364383525<\left(g_{1} / N\right)^{*}$. Thus, in the long run, $K$ is not sustainable when the greenhouse effect is active.

Traditionally, Pigou proposed the Pigouvian tax in order to alleviate pollutions. In the present days, this tax on the consumption of energy is called the environmental tax. In this subsection we examine the effect of environmental tax. Let $\tau$ be the tax rate on the consumption of energy. In other words, for the demanders of energy, they must pay $p_{H}(1+\tau)$, although the tax receipt, $p_{H} \tau$, is distributed to the (aggregate) household. Depending on $\tau$, the convergent per capita food production, $\left(g_{1} / N\right) *[1 / 10$, $\tau]$, can be computed utilizing the simulation for LGED. By definition we have $\left(g_{1} / N\right) *[1 / 10,0]=\left(g_{1} / N\right) *[1 / 10]$.

In Figure 3, $\left(g_{1} / N\right) *[1 / 10, \tau]$ is depicted as a function of $\tau$. It is ascertained that $\left(g_{1} / N\right) *[1 / 10, \tau] \geq\left(g_{1} / N\right) *$ for $\tau$ belonging to the interval $[0.18,22.21], T[1 / 10]$, which is called the sustainability tax range. Note that too high tax rate cannot guarantee the sustainability, whereas too low tax rate cannot either.

\subsection{Active Greenhouse Effect Case: $\alpha_{3}=1 / 4$ and $x_{0}>1 / 10$}

As in 4.2 , when $\alpha_{3}=1 / 4$ and $1 / 10<x_{0}<5 / 10$, in the long run, $K$ is not sustainable when the greenhouse effect is active without remedial measures.

As one of the remedial measures, the environmental tax is required to guarantee the sustainability. For $x_{0}=1 / 10,2 / 10,3 / 10$, and 4/10, corresponding $\left(g_{1} / N\right) *\left[x_{0}\right]$ and sustainable tax range $T\left[x_{0}\right]$ are shown in Table 1.

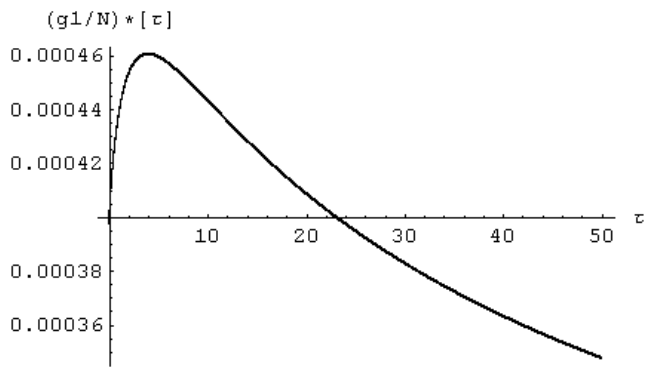

Fig. 3. The Effect of Tax: $x_{0}=1 / 10$

Table 1. The Sustainable Tax Range

\begin{tabular}{lll}
\hline$x_{0}$ & $\left(g_{1} / N\right) *\left[x_{0}\right]$ & $T\left[x_{0}\right]$ \\
\hline 0 & 0.000408248 & \\
$1 / 10$ & 0.000397635364383525 & {$[0.18,22.21]$} \\
$2 / 10$ & 0.000386097395096089 & {$[0.45,16.35]$} \\
$3 / 10$ & 0.000373421126552421 & {$[0.88,12.32]$} \\
$4 / 10$ & 0.000359304111963084 & {$[1.87,7.73]$} \\
\hline
\end{tabular}




\subsection{Active Greenhouse Effect Case: $\alpha_{3}=1 / 4$ and $\boldsymbol{x}_{\mathbf{0}}=\mathbf{5 / 1 0}$}

As in the previous subsections, in the long run, $K$ is not sustainable when the greenhouse effect is active without remedial measures. In Figure $4,\left(g_{1} / N\right) *[5 / 10, \tau]$ is depicted as a function of $\tau$. It is ascertained that $\left(g_{1} / N\right) *[5 / 10, \tau]<\left(g_{1} / N\right) *$ for all $\tau>0$. Thus, when $x_{0}=5 / 10$, it is shown that the environmental tax cannot guarantee the sustainability

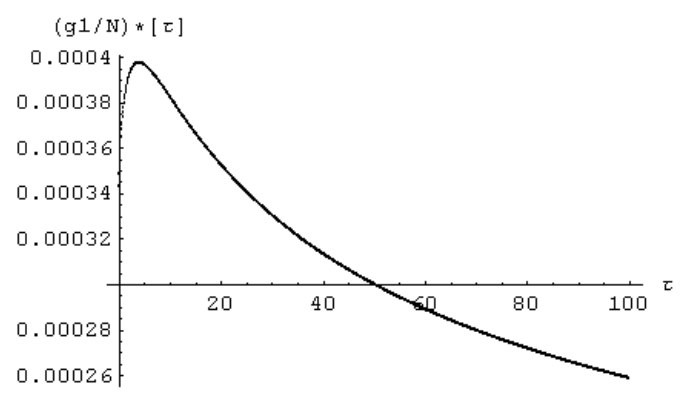

Fig. 4. The Effect of Tax: $x_{0}=5 / 10$

\section{Conclusions}

The aim of this paper is to examine the economic consequences of greenhouse effect, constructing a primitive general equilibrium model by simulation approach. In Section 2, short-run general equilibrium model is constructed, with population and $\mathrm{CO}_{2}$ level assumed constant. In Section 3, the assumption of constant population and $\mathrm{CO}_{2}$ level is relaxed, where the theory of population by Verhulst and Malthus is utilized. In Section 4 by simulation approach on the long run general equilibrium dynamics it was shown that $\mathrm{CO}_{2}$ level converges, while the population converges to the capacity limit, $K$. The converging per capita food consumption, however, might not allow the sustainability of $K$. It is shown that the environmental tax on the energy consumption raises the converging per capita food consumption and it can guarantee the sustainability of $K$ when the greenhouse effect on food production is small. It is shown, furthermore, that the sustainable tax range, which guarantee the sustainability, shrinks as the effect on food production becomes more serious. Finally, it is shown that the sustainable tax range disappears when the effect exceeds a critical level. Thus, we may conclude that the remedial measure to reduce the greenhouse effect other than the environmental tax is needed for the sustainability.

\section{Acknowledgements}

The author appreciates the financial support provided by the Grants-in-Aid for Science Research (Contract Number: 22530181). 


\section{References}

1. Brown, L.R.: State of the World. W.W. Norton \& Company, New York (1987)

2. Fukiharu, T.: A General Equilibrium Approach to Environmental Problems-Enlarged Version. Kobe University Economic Review 37, 13-44 (1991)

3. Fukiharu, T.: Dynamic System Analysis and Environmental Problems. In: Rizzoli, A.E., Jakeman, A.J. (eds.) Proceedings of iEMSs 2002, vol. 2, pp. 586-591 (2002)

4. Fukiharu, T.: The Global Warming, Sustainability and Environmental Tax: A Dynamic General Equilibrium Model (2010),

http: //home.hiroshima-u.ac.jp/fukito/index.htm

5. Malthus, T.R.: An Essay on the Principle of Population, as It affects the Future Improvement of Society, with Remarks on the Speculation of Mr. Godwin, M. Condorcet, and Other Writers, London (1798)

6. Pigou, A.C.: The Economics of Welfare. Macmillan, London (1920)

7. Stern, N.: The Economics of Climate Change: The Stern Review. Cambridge University Press, Cambridge (2007)

8. Verhulst, P.F.: Notice sur la Loi que la Population Poursuit dans son Accroissement. Correspondance Mathématique et Physique 10, 113-121 (1838)

9. Verhulst, P.F.: Recherches Mathematiques sur La Loi D'Accroissement de la Population", Nouveaux Memoires de l'Academie References (1845) 